currency to a branch of physical science, while in the mining industry the results would possess a fundamental significance. For the first time in the history of mineralogical chemistry it is possible, thanks to the researches of Boltwood, Strutt, and McCoy, to predict with considerable certainty the percentage of one element (radium) present if the percentage of another (uranium) is known; and one asks to what this discovery may not grow.

It seems to me that the individual and his single lifetime is too small a stake for the prize in view. Such a work should be national, and carried on from century to century if necessary; and what nation has such a right or such a duty as the one in which the subject of atomic disintegration originated? I confess to a feeling of impatience, to the sense of the inadequacy of the single lifetime, in my experiments on such small quantities of gold as I can purchase, when, disintegrating at the same rate, if disintegrating at all, tons of gold are lying useless in the national bank, their secret-possibly one that it much concerns the race to know-guarded from knowledge by every cunning invention that the art of man may devise. I confess to a sense of indignation that I should have to purchase for my experiments coins and other objects of known antiquity when within the walls of the National Museum lie-mere dead relics as they at present are-one of the finest collections in existence, capable of affording evidence perhaps of a longer history than any dreamed of by the antiquarian, and guarded by those who cannot interpret the cypher, and who, officially at least, are unaware of its existence. I confess to a feeling of misgiving in starting experiments where, on the scale possible to the individual, the chances are all against their yielding a positive result in a lifetime. Surely considerations of this character, the availability of the national resources and antiquities for the purpose of scientific investigations under due safeguards, and the provision for and care of experiments of long period with great quantities demanded by this new subject, are worthy of the attention of the nation, and of the British Science Guild as its newly formed adviser.

The University, Glasgow, December 9.

The suggestion which Mr. Murray has put forward (p. 125) in explanation of the constancy of association of lead and silver has occurred to me also, and is indicated in an article which will probably appear shortly in the "Jahrbuch der Radioactivitat und Elektronik"; some calculations are contained therein which may be of sufficient interest to justify reproduction here.

Some recent experiments ${ }^{1}$ have afforded evidence that the activity of the ordinary metals is caused by the emission of $\alpha$ particles. On the assumption that these $\alpha$ particles have an ionising power similar to that of those from radioactive elements, it appears that lead should emit less than one such particle per second. In order to find the maximum rate of change that we can attribute to this metal, we will assume that the emission of one such particle involves the breaking up of one atom of lead and the formation of one atom of silver; thus one atom breaks up per second. Now a gram of lead contains about $4 \times 10^{21}$ atoms, and therefore to transform one ten-millionth part of the lead would require $4 \times 10^{14}$ seconds or more than ten million years. Since it would be impossible to detect a smaller proportion than this by chemical tests, I fear that the experiment which Mr. Murray suggests is impracticable. The earth would probably have ceased to be a habitable globe by the time that the lead was ripe for examination; perhaps we may trust posterity to settle the matter with greater expedition!

But the slowness of the change in lead presents serious difficulties to the theory that the silver in galena is a disintegration product. Even so small a proportion as one in ten thousand ( $3 \frac{1}{2}$ ounces to the ton) would mean that the silver had been accumulating for a thousand million years-a period longer than that usually assigned as the age of the earth. But until we know more of the processes by which deposits of ore were formed, it is impossible to

1 The accounts of these should be included in an early number of the Philosophical Magazine.

NO. I 885 , VOL. 73$]$ say whether the lead could have retained its silver through all the vicissitudes of its career. I believe that the silver cannot be separated from galena by any physical means; it may be so intimately associated that geological processes cannot affect it; but against this we have to set the fact that cerussite often contains much less silver than the galena from which it is obviously derived. But here chemical separation may have taken place involving the passage of the metals into solution.

There are problems connected with the " traces of impurity" constantly associated with certain minerals which await solution by some laborious chemist; it would be interesting to see whether there is any tendency to proportionality like that which holds between uranium and radium. But the absence of such a relation might be explained on the grounds that radio-active equilibrium had not yet been attained.

There is one other point to which attention may be directed. Rutherford has shown that the loss of heat from the earth by conduction would be compensated by the energy evolved by radium distributed throughout the mass of the earth in the ratio of 1 to $2 \times 10^{13}$; it appears that this amount of energy might be supplied by the disintegration of the actual constituents of the earth even if no radium were present. It is becoming clear that the older estimates of the age of the earth, based on physical data, are wholly erroneous; but if the radio-activity of all elements can be established rigidly, and the time constants of their decay measured with sufficient accuracy, it may be possible to use the evidence to which Mr. Murray has directed attention to gain some information as to the period that has elapsed since the solidification of the earth's crust.

Norman R. Campbell.

Trinity College, Cambridge, December ro.

In Nature, December 7, p. 125, Mr. Donald Murray suggests that the constant association of different elements arises from the slow transmutation of one into the other. The idea is certainly a reasonable one, and I presume has long been in the minds of all who have followed recent work. The writer discussed this question last year (Chem. News, 1904, Ixxxix., 47, 58, 118 ), and arrived at $\mathrm{Mr}$. Murray's opinion.

Now interest in the matter is reviving, perhaps I may be allowed to direct attention to this discussion.

Kiel, December Io. GEOFFREY MARTin.

\section{Action of Wood on a Photographic Plate.}

I HAVE recently seen some photographic plates used at the last eclipse which have on them, not only pictures of the sun, but also pictures of the wood forming the darkslides in which they had been placed.

At a former eclipse I understand a similar disaster occurred. It may, therefore, be well for me again to state that wood in contact with, or in near proximity to, a photographic plate, even in the dark, can impress upon the plate a clear picture of itself. ${ }^{1}$ This action is much stimulated by high temperature and brilliant sunshine. It can, however, be stopped in several ways; probably the simplest one would be to make the slides of copper in place of wood.

Davy-Faraday Laboratory.

\section{Magnetic Storms and Auroræ.}

THE interesting paper by Dr. Chas. Chree in your issue of November 30 (p. ror) is inaccurate in one particular. $\mathrm{He}$ states that the storm of November 12 was not accompanied by auroræ. My friend Mr. John McHarg, of Lisburn, writes me that "it was fairly prominent, to be seen easily above the moonlight, the usual type, a steady glow brighter than the Milky Wav, extending half round the horizon and fading off upwards at an altitude of $20^{\circ}$, or $30^{\circ}$ in the west."

From that station auroræ were also observed on November $14,15,16,17,20,21,22,23,26,27$, and 30 , and it is reported also that a bright crimson arch was seen on the early morning of December I.

6 Eleanor Road, Hackney, N.E.

\section{F. C. Dennetr.}

1 Phil. Trans., vol. cxcvii. p. 28x ; Proc. Roy. Soc., vol. Ixxiv. p. I3r. 